\title{
Determination of hydroxylated polychlorinated biphenyls by offline solid-phase extraction-liquid chromatography-tandem mass spectro- metry using a molecularly imprinted polymer as a sorbent for sample preconcentration
}

\author{
Rongning Liang ${ }^{\mathrm{a}, 1}$, Yan Zhao ${ }^{\mathrm{a}, \mathrm{b}, 1}$, Yang $\mathrm{Su}^{\mathrm{c}}$, Wei Qin ${ }^{\mathrm{a}, *}$ \\ ${ }^{a}$ Key Laboratory of Coastal Environmental Processes and Ecological Remediation, Yantai Institute of Coastal Zone Research (YIC), Chinese Academy of Science \\ (CAS); Shandong Provincial Key Laboratory of Coastal Zone Environmental Processes, YICCAS, Yantai, Shandong 264003, PR China \\ ${ }^{\mathrm{b}}$ University of Chinese Academy of Science, Beijing 100049, PR China \\ ' School of Environment and Materials Engineering, Yantai University, Yantai, Shandong 264003, PR China
}

\section{A R T I C L E I N F O}

\section{Article history:}

Received 5 February 2015

Received in revised form 17 May 2015

Accepted 25 May 2015

Available online 28 May 2015

Keywords:

Dummy molecularly imprinted polymers

Hydroxylated polychlorinated biphenyls

Liquid chromatography mass spectrometry

Solid-phase extraction

\begin{abstract}
A B S T R A C T
Hydroxylated polychlorinated biphenyls (OH-PCBs) can be detected by liquid chromatography-mass spectrometry coupled to solid-phase extraction (SPE) using a dummy molecularly imprinted polymer (DMIP) as a sorbent. The DMIP is prepared by using an analogue of OH-PCBs (i.e., 4, 4-dihydroxybiphenyl) as a dummy template, to avoid the leakage of the target molecules. The DMIP-SPE sorbent shows good recoveries for $\mathrm{OH}-\mathrm{PCBs}$ at $\mathrm{pH} 11$ due to the charge-assisted hydrogen bondings between OH-PCBs and the DMIP. It has been found that the DMIP is much more effective and selective than the traditional $\mathrm{C}_{18^{-}}$ SPE method. The sample $\mathrm{pH}$, polymer dosage, elution solvent and volume have been optimized for higher recoveries. Under the optimum experimental conditions, OH-PCBs can be detected in the linear concentration range of 0.05-1.0 pM, with the detection limits ranging from $11 \mathrm{fM}$ to $82 \mathrm{fM}$ for $4^{\prime}-\mathrm{OH}-\mathrm{CB} 9$, $4^{\prime}-\mathrm{OH}-\mathrm{CB} 30,4^{\prime}-\mathrm{OH}-\mathrm{CB} 61,4^{\prime}-\mathrm{OH}-\mathrm{CB} 106$ and 4'-OH-CB 112. The proposed system has been successfully applied to the determination of trace $\mathrm{OH}-\mathrm{PCBs}$ in spiked water samples with recoveries in the range of 89-110\%.
\end{abstract}

(c) 2015 Elsevier B.V. All rights reserved.

\section{Introduction}

Polychlorinated biphenyls (PCBs) are a class of chlorinated hydrocarbons that had been widely used as insulating fluids, heat carriers and coolants before they were banned in the 1970s. PCBs are persistent organic pollutants due to their bioaccumulative, toxic and persistent properties [1,2]. Hydroxylated polychlorinated biphenyls (OH-PCBs) are produced in the environment by oxidation of PCBs through a variety of mechanisms, including metabolisms in living organisms, reactions with atmospheric active hydroxyl radicals, and transformations in wastewater treatment plants [3-6]. In bacteria and higher organisms, including human beings, $\mathrm{PCBs}$ are metabolized to $\mathrm{OH}-\mathrm{PCB}$ by cytochrome $\mathrm{P}-450$ mono-oxygenases $[7,8]$, which have been found in the blood and tissues of humans and wildlife [9]. A number of OH-PCBs have been identified as endocrine disruptors, therefore, their toxicities

\footnotetext{
* Corresponding author. Fax: +86535 2109000.

E-mail address: wqin@yic.ac.cn (W. Qin).

${ }^{1}$ Both authors contributed equally to this work.
}

may be greater than those of their parent PCBs [10]. OH-PCBs have been detected in aquatic environments such as snow, rain, and surface waters [4], probably produced by aerobic biodegradation of PCBs [11] or by the reactions of PCBs with hydroxyl radicals [12]. Studies show that the concentrations of $\mathrm{OH}-\mathrm{PCB}$ are higher in surface waters near wastewater treatment plants [4], sea waters near shores [13], and ground waters downstream of landfills [14].

Traditionally, measurements of $\mathrm{OH}-\mathrm{PCB}$ can be done using gas chromatography-mass spectrometry (GC-MS) and liquid chromatography-mass spectrometry (LC-MS) [15,16]. For GC-based approaches, sample clean-up and derivatization procedures are always required, which may result in losses in sensitivity due to sample handling and induce more background interferences [16]. Compared to GC-MS, LC-MS methods do not need derivatization of phenolic compounds and therefore are more promising for $\mathrm{OH}-$ PCBs detection $[15,17]$. So far several papers have been reported for LC-MS-based measurements of OH-PCBs in blood matrix [16], but none for measurements in the aquatic environment.

The aim of the present work is to develop an LC-MS detection system to measure $\mathrm{OH}-\mathrm{PCBs}$ in environmental water samples. Prior to detection with LC-MS, preconcentration is crucial for 
sample preparation since the concentrations of $\mathrm{OH}-\mathrm{PCBs}$ in the aquatic environment are quite low. Solid-phase extraction (SPE) is the most commonly used method for extraction and preconcentration of target analytes from environmental samples [18]. However, traditional sorbents of SPE like $C_{18}$ silica gel are mainly based on non-specific adsorption rather than selective molecular recognition. Currently, molecularly imprinted polymers (MIPs) as SPE sorbents have attracted considerable attention for ease of use and high binding selectivites [19]. However, the drawback of the MIP technique is the leakage of template molecules from the polymer matrix, which may cause false-positive results especially for trace analysis [20]. To overcome this problem, dummy templates, which are analogous to the target molecules, have been applied to design and synthesize "dummy molecularly imprinted polymers" (DMIPs). So far, only Kubo et al. [21] reported the synthesis of DMIPs for OH-PCBs and evaluated their selective separation abilities by using liquid chromatography. The application of DMIPs as SPE sorbents for LC-MS detection of OH-PCBs in the aquatic environment has not been investigated. Herein, we report the preparation of the DMIP for OH-PCBs by using 4,4'-dihydroxybiphenyl as the dummy template, and the application of the DMIP as the SPE sorbent for preconcentration of OH-PCBs from environmental water samples. We show that the DMIP can be successfully applied to SPE coupled with LC-MS/MS to determine trace amounts of $\mathrm{OH}-\mathrm{PCBs}$ in the aquatic environment.

\section{Experimental}

\subsection{Materials and reagents}

The dummy template 4,4'-dihydroxybiphenyl (97\%) and analytical standards of OH-PCBs congeners including 4'-hydroxy-2,5dichlorobiphenyl (4'-OH-CB 9), 4'-hydroxy-2,4,6-trichlorobiphenyl (4'-OH-CB 30), 4'-hydroxy-2,3,4,5-tetrachloro- biphenyl (4'-OH-CB 61 ), 4'-hydroxy-2,3,3',4,5-pentachlorobiphenyl (4'-OH-CB 106), 4'hydroxy-2,3,3',5,6-pentachlorobiphenyl (4'-OH-CB 112), and PCBs congeners including $2^{\prime}, 2,4,5,5^{\prime}$-pentachlorobiphenyl (PCB 101) and 2,3,3',4,4',5-hexachloro- biphenyl (PCB 156) were purchased from Accustandard Inc. (New Haven, CT, USA). Stock solutions of OHPCBs $(1.0 \mu \mathrm{M})$ were prepared in methanol. Working solutions were prepared by gradual dilutions of the stock solutions with water. Methanol, acetonitrile (ACN), n-hexane and ethyl acetate (EtOAc) were all of HPLC-reagent grade and acquired from Shanghai ANPEL Scientific Instrument Co., Ltd. (Shanghai, China). The functional monomer acrylamide (AAM), cross-linker trimethylolpropane trimethacrylate (TRIM) and initiator 2,2'-azobisisobutyronitrle (AIBN) were obtained from Sigma-Aldrich. The $\mathrm{C}_{18}$-SPE cartridges were obtained from ANPEL (Shanghai, China). Deionized water (18.2 $\mathrm{M} \Omega \mathrm{cm}^{-1}$ specific resistance) was obtained from a Pall Cascada laboratory water system. All the other chemicals were of analytical grade.

\subsection{Preparation of the dummy molecularly imprinted polymer}

MIPs were synthesized by using the precipitation polymerization method. $93.11 \mathrm{mg}$ of 4,4'-dihydroxybiphenyl and $213.24 \mathrm{mg}$ of functional monomer AAM were dissolved with ACN $(30 \mathrm{~mL})$ in a $45 \mathrm{~mL}$ screw-capped glass tube. The mixture was sonicated, and then placed in darkness for 1 hour. After that, $0.958 \mathrm{~mL}$ of the cross-linker TRIM and $50 \mathrm{mg}$ of AIBN were added to the mixture. The resulting mixture was purged with nitrogen for $10 \mathrm{~min}$ and then polymerized at $70{ }^{\circ} \mathrm{C}$ in oil bath for $24 \mathrm{~h}$. The obtained polymer was collected by vacuum filtration, and packed into the Soxhlet extractor with a filter paper sleeve. The polymer was washed circularly with $150 \mathrm{~mL}$ of methanol/acetic acid (9/1, v/v) for $24 \mathrm{~h}$, and further washed 3 times with $120 \mathrm{~mL}$ of methanol for $8 \mathrm{~h}$. The resulting polymer was dried overnight in a vacuum oven at $45{ }^{\circ} \mathrm{C}$. The corresponding non-imprinted polymers were synthesized using the same procedure in the absence of the template molecules.

\subsection{Preconcentration of $\mathrm{OH}-\mathrm{PCBS}$ using DMIP-SPE}

In order to evaluate the adsorption affinity of the DMIP to $\mathrm{OH}$ PCBs, a traditional SPE procedure was performed using a SPE cartridge. The SPE tubes $(3.0 \mathrm{~mL}$, i.d. $1.0 \mathrm{~cm})$ were packed with $50 \mathrm{mg}$ of the dry DMIP or NIP by using two PTFE frits at both ends. The SPE cartridges were preconditioned with $5 \mathrm{~mL}$ of ACN to activate the sorbent before the enrichment procedure. Water samples of $1 \mathrm{~L}$ containing $1 \mathrm{mM} \mathrm{NaOH}$ spiked with different concentrations of OH-PCBs were passed through the SPE cartridge at $30 \mathrm{~mL} \mathrm{~min}^{-1}$, and then washed with $20 \mathrm{~mL}$ of water. After loading, the vacuum was still applied to the cartridge for $1 \mathrm{~min}$ in order to remove the residual solvent. The elution step was performed using $10 \mathrm{~mL}$ of the mixture of hexane and EtOAc $(1 / 1, \mathrm{v} / \mathrm{v})$. The eluent was collected and dried at $60^{\circ} \mathrm{C}$ under a gentle nitrogen stream. The residue was dissolved in $100 \mu \mathrm{L}$ of methanol and analyzed by LC-MS/MS.

\subsection{Recovery tests}

The recovery measurements of molecularly imprinted solidphase extraction (MISPE) for OH-PCBs were carried out by using a reversed-phase HPLC system which consists of a Waters Alliance e2695 separations module with a Waters 2998 photo-diode array detector, and a Waters Sunfire $C_{18}$ reversed-phase column $\left(4.6 \times 250 \mathrm{~mm}^{2}, 5 \mu \mathrm{m}\right)$. Methanol $/ \mathrm{H}_{2} \mathrm{O}(90 / 10, \mathrm{v} / \mathrm{v})$ was used as mobile phase with a flow rate of $1.0 \mathrm{~mL} \mathrm{~min}^{-1}$ and the column temperature was $40{ }^{\circ} \mathrm{C}$.

The recoveries were calculated as follows:

Recovery $=C_{\mathrm{f}} \cdot V_{\mathrm{f}} / C_{\mathrm{i}} \cdot V_{\mathrm{i}} \times 100 \%$

where $C_{i}$ and $C_{f}$ are the initial and final concentrations of OH-PCB in the sample solution, respectively, and $V_{i}$ and $V_{f}$ are the volumes of the solution before and after the MISPE process, respectively.

\subsection{LC-ESI(-)-MS/MS measurements}

Chromatographic analyses were carried out using a Thermo Accela HPLC system consisting of an Accela autosampler and an Accela 1250 pump. The separation was achieved using a Waters Sunfire $C_{18}$ reversed-phase column $\left(4.6 \times 250 \mathrm{~mm}^{2}, 5 \mu \mathrm{m}\right)$ with a mobile phase flow rate of $1.0 \mathrm{~mL} \mathrm{~min}^{-1}$. A sample of $20 \mu \mathrm{L}$ was auto-injected into the HPLC column maintained at $30^{\circ} \mathrm{C}$. The mobile phase used was methanol and water, which was applied in a linear gradient from $84 \%$ to $95 \%(\mathrm{v} / \mathrm{v})$ methanol in the first $16 \mathrm{~min}$, and then maintained 95\% (v/v) methanol until $20 \mathrm{~min}$. The column was equilibrated with $84 \%(\mathrm{v} / \mathrm{v})$ methanol solution for 5 min before the subsequent injection.

Mass spectrometric detection was performed using a Thermo Fisher TSQ Quantum Access MAX tandem quadrupole mass spectrometer (Thermo Fisher, CA, USA) equipped with an electrospray ionization-II (HESI-II) interface operating in the negative ion mode. The spray voltage was set at $3.0 \mathrm{kV}$. The sheath pressure and auxiliary gas (all $\mathrm{N}_{2}$ ) pressure were set at 30 and 10 arbitrary unit (Arb), respectively. The capillary temperature was kept at $300{ }^{\circ} \mathrm{C}$. The collision gas pressure was adjusted to $1.0 \mathrm{mTorr}$. ESI(-)-MS/MS parameters were chose for maximum ion current of the $[\mathrm{M}-\mathrm{H}]$ -isotopic cluster for each HO-PCB congener. Data acquisition and processing were achieved using the Thermo Scientific Xcalibur 
Table 1

Data for the LC-MS/MS analysis of the target compounds.

\begin{tabular}{|c|c|c|c|c|c|c|c|}
\hline IUPAC full chemical name & Abbreviation & Structure & $p K_{\mathrm{a}}[36]$ & Retention time (min) & Molecular weight & Qualitative ion & Quantitative ion \\
\hline 4'-Hydroxy-2,5-dichlorobiphenyl & $4^{\prime}-\mathrm{OH}-\mathrm{CB} 9$ & & 9.50 & 6.25 & 237 & $\begin{array}{l}\text { 165.3 } \\
201.1\end{array}$ & 201.1 \\
\hline 4'-Hydroxy-2,4,6-trichlorobiphenyl & $4^{\prime}-\mathrm{OH}-\mathrm{CB} 30$ & & 9.44 & 7.99 & 271 & $\begin{array}{l}199.2 \\
235.0\end{array}$ & 235.0 \\
\hline 4'-Hydroxy-2,3,4,5-tetrachlorobiphenyl & $4^{\prime}-\mathrm{OH}-\mathrm{CB} 61$ & & 9.41 & 11.61 & 305 & $\begin{array}{l}233.1 \\
268.9\end{array}$ & 268.9 \\
\hline $4^{\prime}$-hydroxy-2,3,3',4,5-pentachlorobiphenyl & 4'-OH-CB 106 & & 7.84 & 13.65 & 339 & $\begin{array}{l}266.9 \\
302.9\end{array}$ & 302.9 \\
\hline 4'-hydroxy-2,3,3',5,6-pentachlorobiphenyl & 4'-OH-CB 112 & & 7.80 & 10.96 & 339 & $\begin{array}{l}266.9 \\
302.9\end{array}$ & 302.9 \\
\hline
\end{tabular}

2.1 SP1 data software. The data of all the analytes are shown in Table 1.

\subsection{Sample preparation}

Waste water samples were collected from a sewage treatment plant (Yantai, China). Sea water samples were collected from near shores of the Bohai Sea (Yantai, China). All the water samples were filtered through $0.45 \mu \mathrm{m}$ microporous glass membranes and stored in brown volumetric glass flask. All the samples were adjusted to $\mathrm{pH} 11.0$ before measurements. Unless otherwise stated, the concentration fold was 10,000 by using the proposed DMISPE in this work.

\section{Results and discussion}

\subsection{Characterization of the DMIP as SPE sorbent}

The noncovalent molecular imprinting method was employed to prepare the DMIP for OH-PCBs. The hydroxyl group of the template 4,4'-dihydroxybiphenyl can form strong hydrogen bonding with the functional monomer AAM when the template is mixed with AAM in darkness. In addition, a charge-transfer complexing interaction takes place between the electron-deficient aromatic ring of biphenyl and the electron-rich amino group of AAM in solution system $[22,23]$. The surface morphologies of the obtained DMIP and NIP of OH-PCBs were characterized by scanning electron microscopy (SEM). As shown in Fig. 1, the imprinted particles show a uniform spherical shape with a narrow size distribution of 2-3 $\mu \mathrm{m}$, whereas the non-imprinted particles are irregular and much smaller, which indicates that the template could influence the polymer formation. Indeed, it has been found that the template-monomer complex can change the solubility of the growing polymer, thus altering the polymer morphology [24,25].

To identify the superiority of the DMIP, comparison among the DMIP, $C_{18}$ silica gel and the NIP for SPE was made. Fig. 2 shows that OH-PCBs can be retained on the DMIP-SPE column with the recoveries higher than $80 \%$, while only about $40 \%$ of OH-PCBs can be recovered on the NIP or $\mathrm{C}_{18}$ SPE column. The high recoveries of DMIP for OH-PCBs are due to the high-affinity bindings of the imprinted polymer to the OH-PCB molecules.

The selective extraction was also studied on the DMIP column by testing the recoveries of OH-PCBs (e.g., 4'-OH-CB 106 and 4'$\mathrm{OH}-\mathrm{CB}$ 112) and their structural analogues (e.g., biphenyl, PCB-101, and PCB-156). As also shown in Fig. 2, OH-PCBs can be selectively retained on the MIP column with the high recoveries of $80-90 \%$, but biphenyl and PCBs are poorly retained with the low recoveries of less than $45 \%$. Therefore, the high SPE selectivity of DMIP for $\mathrm{OH}-\mathrm{PCBs}$ is evident.

\subsection{Optimization of DMIP-SPE parameters}

To obtain the best extraction efficiency for OH-PCBs, the DMIPSPE conditions, including the $\mathrm{pH}$ of sample solution, the amount of the MIP sorbent, the type and volume of the eluting solvent, were optimized in this study.

\subsubsection{Effect of sample $p H$}

Sample $\mathrm{pH}$ affects the binding interactions including hydrogen bonding and ionic interactions between the analytes and the MIP monolith, and thus influences the adsorption efficiency of DMIPSPE [26-28]. Therefore, the effect of sample pH on the recovery of $\mathrm{OH}-\mathrm{PCBs}$ was tested in the $\mathrm{pH}$ range of $3.0-11.0$. The results are
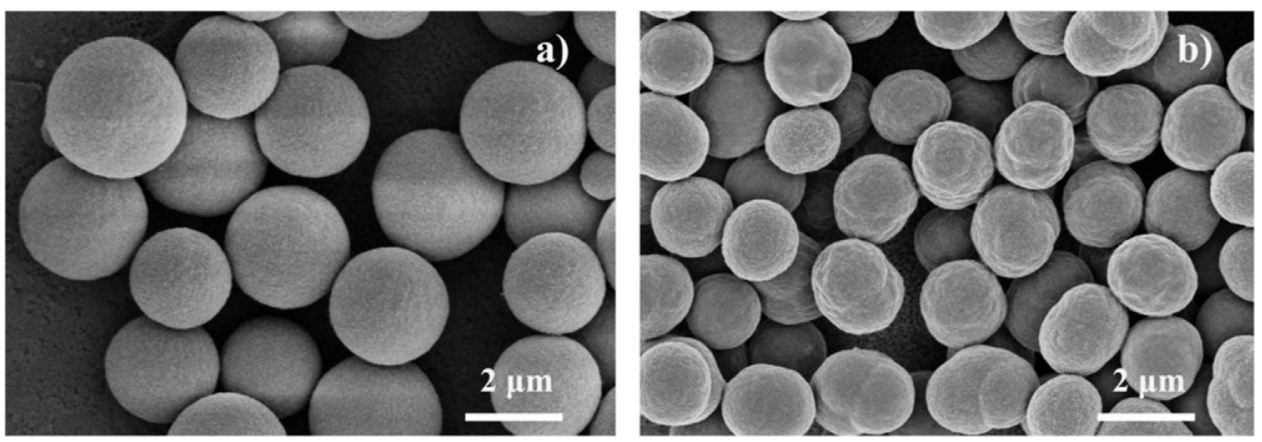

Fig. 1. SEM images of DMIP (a) and NIP (b). 


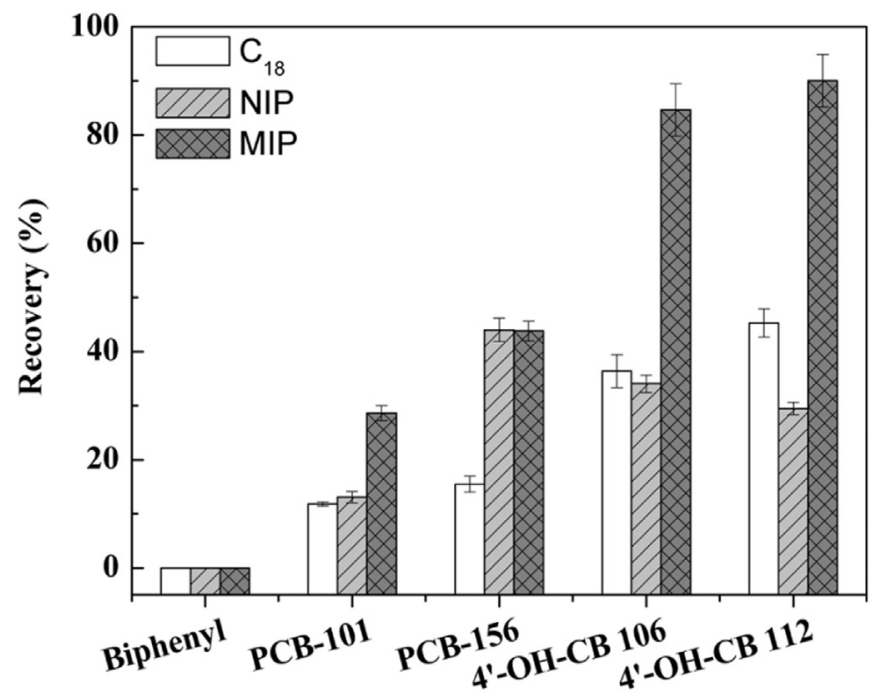

Fig. 2. Recoveries of biphenyl, PCBs and OH-PCBs on the DMIP, NIP and $\mathrm{C}_{18}$ columns. Conditioning solutions, $5 \mathrm{~mL} \mathrm{ACN}$ and then $5 \mathrm{~mL}$ deionized water; sample volume, $1000 \mathrm{~mL}$; sample concentrations, $1 \mathrm{nM}$ for OH-PCBs, $10 \mathrm{nM}$ for biphenyl and $10 \mathrm{nM}$ for PCBs; sample $\mathrm{pH}, 11.0$; MIP sorbent, $50 \mathrm{mg}$; eluent solution, $10 \mathrm{~mL}$ hexane/EtOAc (1/1, v/v); washing solution, $20 \mathrm{~mL}$ deionized water. Each error bar represents the standard deviation of three measurements.

shown in Fig. 3, it can be seen that at pH 11.0, the proposed DMIPSPE column exhibits the highest recovery. This is probably due to the fact that at $\mathrm{pH} 11.0, \mathrm{OH}-\mathrm{PCB}$ would be dissociated and negatively charged, therefore the charge-assisted $\mathrm{N}-\mathrm{H} \ldots \mathrm{O}^{(-)}$hydrogen bonding interactions will be formed between OH-PCBs and the polymer $[29,30]$. In addition, it should be noted that a relatively high recovery can also be observed at $\mathrm{pH}$ 3.0. This can be attributed to the fact that the $-\mathrm{NH}_{2}$ groups in the imprinted polymer can be protonated, and thus the strong cation $-\pi$ interactions between the $-\mathrm{NH}_{2}$ groups and the benzene rings of OH-PCBs can be formed $[31,32]$.

\subsubsection{Influence of the amount of MIP sorbent}

The influence of the amount of MIP sorbent on the recovery of $\mathrm{OH}-\mathrm{PCBs}$ was investigated by varying the amount of MIP sorbent from 10 to $70 \mathrm{mg}$. As shown in Fig. 4, the recoveries of OH-PCBs increase with increasing the amount of DMIP sorbent up to $50 \mathrm{mg}$, which is attributed to the increase in the number of binding sites

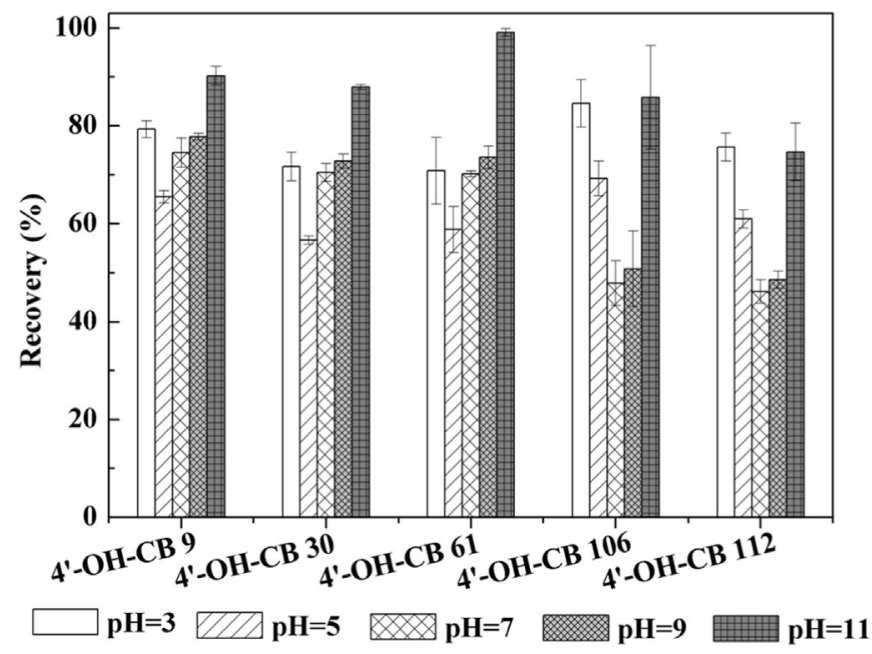

Fig. 3. Effect of sample $\mathrm{pH}$ on the recoveries of the five OH-PCBs congeners. The other conditions are as given in Fig. 2. Each error bar represents the standard deviation of three measurements.

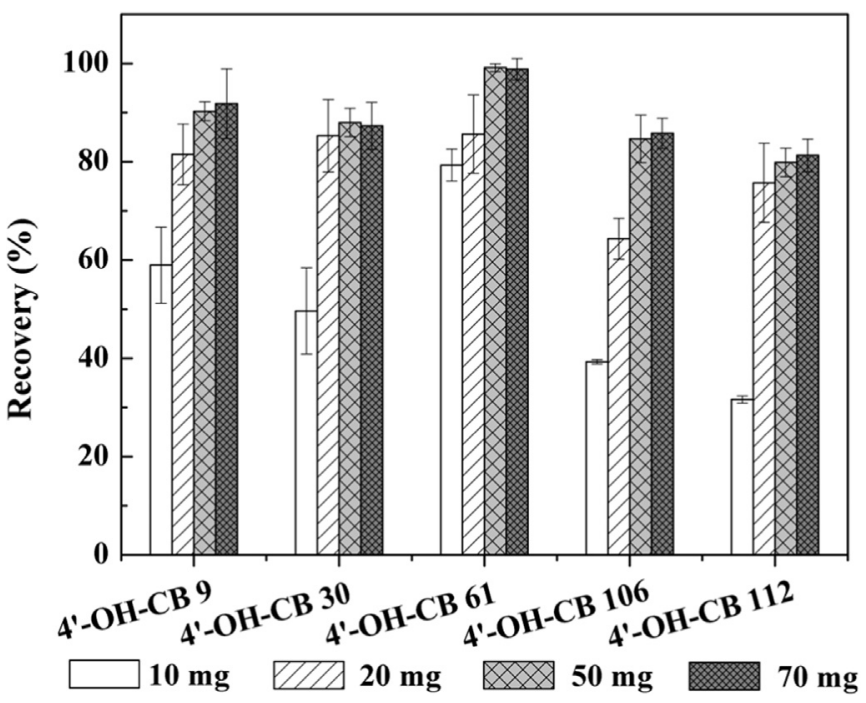

Fig. 4. Effect of the amount of MIP sorbent on the recoveries of the five OH-PCBs congeners. The other conditions are as given in Fig. 2. Each error bar represents the standard deviation of three measurements.

of the DMIP sorbent for selective extraction of $\mathrm{OH}-\mathrm{PCB}$ from sample solution. However, further increase in the amount of DMIP sorbent would not significantly improve the recovery. Therefore, $50 \mathrm{mg}$ of DMIP sorbent was employed for subsequent experiments.

\subsubsection{Effects of the eluent and eluting volume}

Several solvents including hexane, EtOAc, ACN, and the mixture of hexane/EtOAc $(1 / 1, v / v)$ were tested for efficient elution of $\mathrm{OH}$ PCBs $[33,34]$. As shown in Fig. 5, the recoveries of OH-PCBs congeners eluted by hexane are less than $40 \%$, while the average recoveries exceed $60 \%$ for EtOAc and $50 \%$ for ACN. In addition, the mixture of n-hexane/EtOAc exhibits an average recovery of $>80 \%$. Indeed, this mixture is usually used to extract OH-PCBs from tissues and blood [35]. Therefore, the mixture of hexane/EtOAc (1/1, $\mathrm{v} / \mathrm{v}$ ) was used to elute the MISPE cartridge for the present system.

Since the sample extraction efficiency also depends on the volume of the eluent, the effect of the volume of the hexane/EtOAc mixture was also evaluated. As show in Fig. 6, for the tested five $\mathrm{OH}-\mathrm{PCBs}$ congeners, the recoveries increase upon increasing the volume of the eluent up to $10 \mathrm{~mL}$, which is due to the fact that

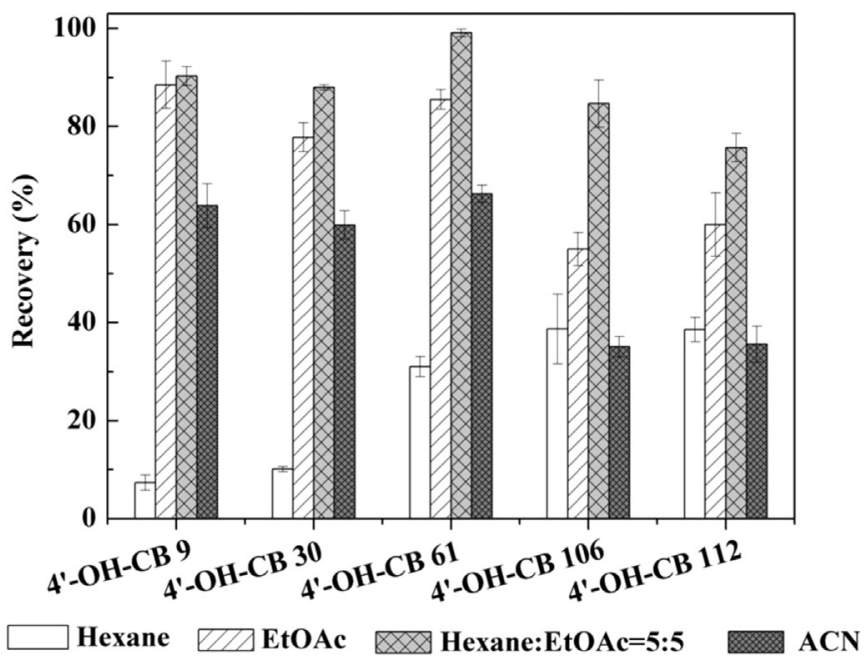

Fig. 5. Effect of the elution solvent on the recoveries of the five OH-PCBs congeners. The other conditions are as given in Fig. 2. Each error bar represents the standard deviation of three measurements. 


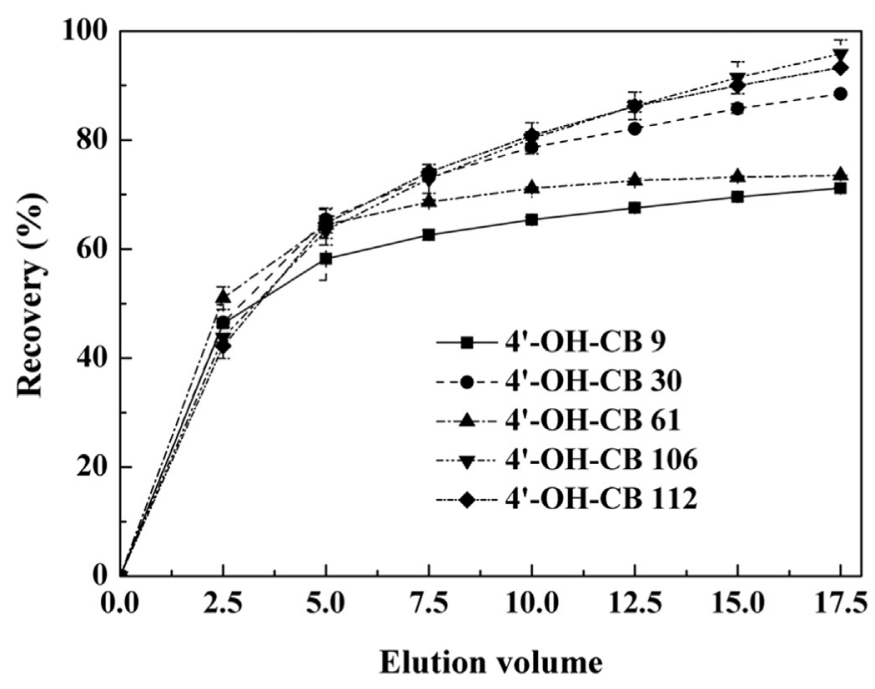

Fig. 6. Effect of the elution volume on the recoveries of OH-PCBs. The other conditions are as given in Fig. 2. Each error bar represents the standard deviation of three measurements.

larger amounts of eluent could release more OH-PCBs from the MISPE cartridge. Fig. 6 also shows that further increasing the eluent volume cannot increase the detection sensitivity significantly. In addition, it should be noted that larger amounts of eluent would prolong the detection procedure. Considering a compromise between higher recovery and shorter analysis time, a volume of $10 \mathrm{~mL}$ of hexane/EtOAc mixture was selected for the eluting process.

\subsection{Determination of OH-PCBs by offline MISPE-LC-MS/MS}

Under the optimized conditions, the analytical characteristics of the proposed offline MISPE-LC-MS/MS system were investigated. The OH-PCBs were identified by their corresponding chromatographic retention time and MS/MS spectrum. The fragment ions of $\mathrm{m} / \mathrm{z} 165.3$ and 201.1 for $4^{\prime}-\mathrm{OH}-\mathrm{CB} 9, \mathrm{~m} / \mathrm{z} 199.2$ and 235.0 for $4^{\prime}-\mathrm{OH}-\mathrm{CB} 30, \mathrm{~m} / \mathrm{z} 233.1$ and 268.7 for $4^{\prime}-\mathrm{OH}-\mathrm{CB} 61, \mathrm{~m} / \mathrm{z}$ 266.9 and 302.9 for both $4^{\prime}-\mathrm{OH}-\mathrm{CB} 106$ and $4^{\prime}-\mathrm{OH}-\mathrm{CB}$ 112, were selected for identification. In this study, the strongest specific fragment ions of $\mathrm{m} / \mathrm{z} 201.1$ for $4^{\prime}-\mathrm{OH}-\mathrm{CB} 9, \mathrm{~m} / \mathrm{z} 235.0$ for $4^{\prime}-\mathrm{OH}-\mathrm{CB}$ $30, \mathrm{~m} / \mathrm{z} 268.9$ for $4^{\prime}-\mathrm{OH}-\mathrm{CB} 61$, and $\mathrm{m} / \mathrm{z} 302.9$ for both $4^{\prime}-\mathrm{OH}-\mathrm{CB}$ 106 and $4^{\prime}-\mathrm{OH}-\mathrm{CB} 112$, were selected to quantify the concentrations. Table 2 displays the characteristics of the proposed system for the five $\mathrm{OH}-\mathrm{PCBs}$ congeners. It can be seen that the system exhibits the linear concentration range of $0.05-1.0 \mathrm{pM}$ for $4^{\prime}-\mathrm{OH}-$ CB 9, 4'-OH-CB 30, 4'-OH-CB 61, 4'-OH-CB 106 and 4'-OH-CB 112. The limits of detection (LODs) were calculated as the minimum detectable amount of analyte with a signal-to-noise of 3. The LOD values are in the range of $11-82 \mathrm{fM}\left(3-28 \mathrm{pg} \mathrm{L}^{-1}\right)$, which are comparable to those reported in the literature [4]. Notably, it has been shown that the total concentrations of OH-PCBs in surface waters from sites near sewage treatment plant outfalls in the cities

Table 2

The linear ranges, correlation coefficients $\left(R^{2}\right)$ and LODs of the proposed method $(n=5)$.

\begin{tabular}{lllll}
\hline Compounds & Linear range (pM) & $R^{2}$ & RSD $(n=5)$ & LOD (fM) \\
\hline $4^{\prime}$-OH-CB 9 & $0.05-1.0$ & 0.998 & 6.4 & 25 \\
$4^{\prime}-\mathrm{OH}-\mathrm{CB} \mathrm{30}$ & $0.05-1.0$ & 0.998 & 4.5 & 11 \\
4'-OH-CB 61 $^{\prime}$ & $0.05-1.0$ & 0.972 & 4.9 & 13 \\
4'-OH-CB 106 $^{\prime}-0.05-1.0$ & 0.996 & 3.7 & 28 \\
4'-OH-CB 112 $^{\prime}-0.05-1.0$ & 0.997 & 7.6 & 82 \\
\hline
\end{tabular}

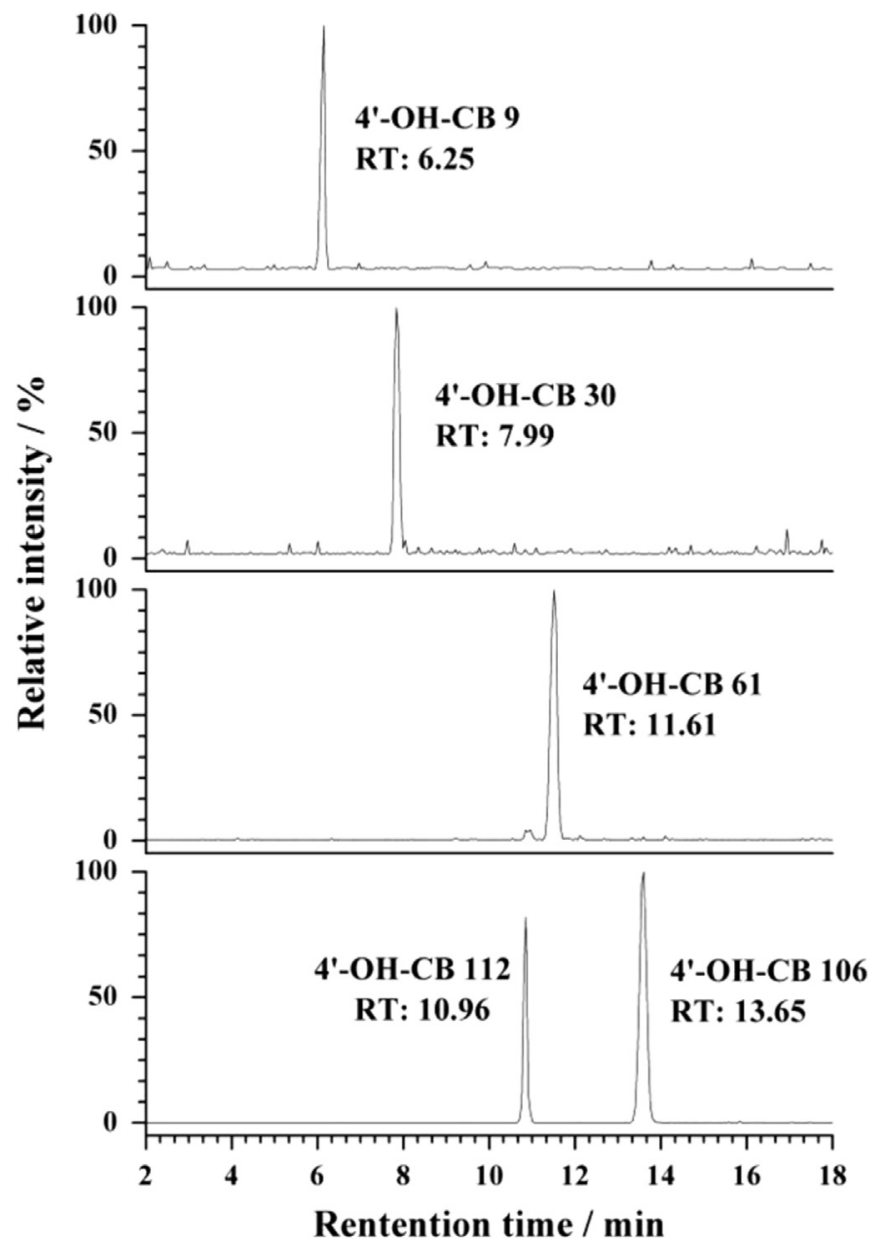

Fig. 7. LC-ESI(-)-MS/MS chromatograms of OH-PCBs obtain from sea water sample spiked with $0.1 \mathrm{pM}$ of each analyte after the MISPE preconcentration.

of Toronto and Hamilton were 130 and $35 \mathrm{pg} \mathrm{L}^{-1}$, respectively [4]. Hence, the proposed system has promising feasibility for tracelevel measurements of $\mathrm{OH}-\mathrm{PCBs}$ in real environmental water samples. In addition, the relative standard deviation (RSD) for five measurements was found to be in the range of 3.7-7.6\%. These results indicate that the developed method exhibits high sensitivity and good reproducibility for $\mathrm{OH}-\mathrm{PCB}$ determination.

\subsection{Analysis of $\mathrm{OH}-\mathrm{PCBs}$ in spiked water samples}

In order to evaluate the feasibility in practical analysis, the proposed MISPE-LC-MS/MS method was applied to determine $\mathrm{OH}-\mathrm{PCB}$ in surface water near shore and waste water in sewage treatment plants. The standard addition method was used to verify the accuracy and precision of the proposed method. Notably, we firstly performed the direct detection of $\mathrm{OH}-\mathrm{PCBs}$ in the above mentioned samples. Unfortunately, these samples are undetectable (data not shown). This is probably owing to the low concentrations of OH-PCBs in the samples which are below the detection limit of the proposed method. Fig. 7 shows chromatograms obtained from the spiked samples. As shown in Table 3, under the optimum conditions, the measured recoveries of the proposed method for five $\mathrm{OH}-\mathrm{PCBs}$ in sea water and waste water samples were $98-110 \%$ and $89-109 \%$, respectively, with the RSD values lower than $11 \%$, indicating that the proposed system has a promising potential for real sample analysis with a high accuracy and good reliability. 
Table 3

Validation data of the proposed method $(n=5)$.

\begin{tabular}{|c|c|c|c|c|c|c|}
\hline \multirow[t]{2}{*}{ Compounds } & \multicolumn{3}{|l|}{ Sea water } & \multicolumn{3}{|l|}{ Waste water } \\
\hline & Spiked level (fM) & Found level (fM) & Recovery (\%) & Spiked level (pM) & Found level (pM) & Recovery (\%) \\
\hline $4^{\prime}-\mathrm{OH}-\mathrm{CB} 9$ & 100 & $104( \pm 11)$ & 104 & 1.00 & $0.92( \pm 0.08)$ & 92 \\
\hline $4^{\prime}-\mathrm{OH}-\mathrm{CB} 30$ & 100 & $98( \pm 10)$ & 98 & 1.00 & $1.04( \pm 0.03)$ & 104 \\
\hline $4^{\prime}-\mathrm{OH}-\mathrm{CB} 61$ & 100 & $110( \pm 10)$ & 110 & 1.00 & $0.89( \pm 0.08)$ & 89 \\
\hline 4'-OH-CB 106 & 100 & $107( \pm 3)$ & 107 & 1.00 & $1.02( \pm 0.01)$ & 102 \\
\hline 4'-OH-CB 112 & 100 & $102( \pm 6)$ & 102 & 1.00 & $1.09( \pm 0.10)$ & 109 \\
\hline
\end{tabular}

\section{Conclusions}

A new method for sensitive and selective determination of $\mathrm{OH}-$ PCBs has been developed, based on the combination of the MISPE and LC-MS/MS. The MIP is prepared by the precipitation polymerization method using a dummy template rather than the $\mathrm{OH}-$ PCB analyte. The resulting DMIP shows good recovery and high specific recognition ability for OH-PCBs. Combined with LC-MS/ MS, the DMIP based SPE column has been used to determine OHPCBs in the environmental samples. The proposed MISPE-LC-MS/ MS method is promising for the trace-level analysis of OH-PCBs in complex samples.

\section{Acknowledgements}

This work was financially supported by the Instrument Developing Project of the Chinese Academy of Sciences (YZ201161), the National Natural Science Foundation of China (41206087, 20977073, and 21475148), and the Taishan Scholar Program of Shandong Province.

\section{References}

[1] S.H. Safe, Polychlorinated biphenyls (PCBs): environmental impact, biochemical and toxic responses, and implications for risk assessment, Crit. Rev. Toxicol. 24 (1994) 87-149.

[2] S. Takeuchi, F. Shiraishi, S. Kitamura, H. Kuroki, K. Jin, H. Kojima, Characterzation of steroid hormone receptor activities in 100 hydroxylated polychlorinated biphenyls, including congeners identified in humans, Toxicology 289 (2011) 112-121.

[3] P.N. Anderson, R.A. Hites, OH radical reactions: the major removal pathway for polychlorinated biphenyls from the atmosphere, Environ. Sci. Technol. 30 (1996) 1756-1763.

[4] D. Ueno, C. Darling, M. Alaee, L. Campbell, G. Pacepavicius, C. Teixeira, D. Muir, Detection of hydroxylated polychlorinated biphenyls (OH-PCBs) in the abiotic environment: surface water and precipitation from Ontario, Canada, Environ. Sci. Technol. 41 (2007) 1841-1848.

[5] R. Tehrani, B. Van Aken, Hydroxylated polychlorinated biphenyls in the environment: sources, fate, and toxicities, Environ. Sci. Pollut. Res. 21 (2014) 6334-6345.

[6] K. Nomiyama, T. Tanizaki, H. Ishibashi, K. Arizono, R. Shinohara, Production mechanism of hydroxylated PCBs by oxidative degradation of selected PCBs using TiO2 in water and estrogenic activity of their intermediates, Environ. Sci. Technol. 39 (2005) 8762-8769.

[7] R.J. Letcher, E. Klasson-Wehler, Å. Bergman, Methyl sulfone and hydroxylated metabolites of polychlorinated biphenyls, in: J. Paasivirta (Ed.), The Handbook of Environmental Chemistry: New Types of Persistent Halogeated Compounds, Part K vol 3, SpringerVerlag, Heidelberg, Germany, 2000, pp. 315-359.

[8] J.A. Field, R. Sierra-Alvarez, Microbial transformation and degradation of polychlorinated biphenyls, Environ. Pollut. 155 (2008) 1-12.

[9] K. Nomiyama, T. Yonehara, S. Yonemura, M. Yamamoto, C. Koriyama, S. Akiba, R. Shinohara, M. Koga, Determination and characterization of hydroxylated polychlorinated biphenyls (OH-PCBs) in serum and adipose tissue of Japanese women diagnosed with breast cancer, Environ. Sci. Technol. 44 (2009) 2890-2896.

[10] K. Teasley Hamorsky, C.M. Ensor, E. Dikici, P. Pasini, L. Bachas, S. Daunert, Bioluminescence inhibition assay for the detection of hydroxylated polychlorinated biphenyls, Anal. Chem. 84 (2012) 7648-7655.

[11] M. Harkness, J. McDermott, D. Abramowicz, J. Salvo, W. Flanagan, M. Stephens, F. Mondello, R. May, J. Lobos, K. Carroll, In situ stimulation of aerobic PCB biodegradation in Hudson River sediments, Science 259 (1993) 503-507.
[12] D.L. Sedlak, A.W. Andren, The effect of sorption on the oxidation of polychlorinated biphenyls (PCBs) by hydroxyl radical, Water Res. 28 (1994) 1207-1215.

[13] C. Darling, M. Alaee, L. Campbell, G. Pacepavicius, D. Ueno, D. Muir, Hydroxylated PCBs in abiotic environmental matrices: precipitation and surface waters, Organohalog. Compd. 66 (2004) 1470-1475.

[14] B. Kuch, F. Kern, J.W. Metzger, K.T. von der Trenck, Effect-related monitoring estrogen-like substances in groundwater, Environ. Sci. Pollut. Res. 17 (2010) $250-260$.

15] U. Berger, D. Herzke, T.M. Sandanger, Two trace analytical methods for determination of hydroxylated PCBs and other halogenated phenolic compounds in eggs from Norwegian birds of prey, Anal. Chem. 76 (2004) 441-452.

[16] R. Letcher, H. Li, S. Chu, Determination of hydroxylated polychlorinated biphenyls (HO-PCBs) in blood plasma by high-performance liquid chromatography-electrospray ionization-tandem quadrupole mass spectrometry, J. Anal. Toxicol. 29 (2005) 209-216.

[17] G.S. Zhai, X.A. Wu, H.J. Lehmler, J.L. Schnoor, Atropisomeric determination of chiral hydroxylated metabolites of polychlorinated biphenyls using HPLC-MS, Chem. Cent. J. 7 (2013) 183.

[18] S. Rubio, D. Perez-Bendito, Recent advances in environmental analysis, Anal. Chem. 81 (2009) 4601-4622.

[19] E. Caro, R.M. Marce, F. Borrull, P.A.G. Cormack, D.C. Sherrington, Application of molecularly imprinted polymers to solid-phase extraction of compounds from environmental and biological samples, TrAC, Trends Anal. Chem. 25 (2006) 143-154.

[20] X. Feas, J.A. Seijas, M.P. Vazquez-Tato, P. Regal, A. Cepeda, C. Fente, Syntheses of molecularly imprinted polymers: molecular recognition of cyproheptadine using original print molecules and azatadine as dummy templates, Anal. Chim. Acta 631 (2009) 237-244.

[21] T. Kubo, H. Matsumoto, F. Shiraishi, M. Nomachi, K. Nemoto, K. Hosoya, K. Kaya, Selective separation of hydroxy polychlorinated biphenyls (HO-PCBs) by the structural recognition on the molecularly imprinted polymers: direct separation of the thyroid hormone active analogues from mixtures, Anal. Chim. Acta 589 (2007) 180-185.

[22] S. Kang, J.P. Green, Steric and electronic relationships among some hallucinogenic compounds, Proc. Natl. Acad. Sci. U.S.A. 67 (1970) 62-67.

[23] A. Rose, Z. Zhu, C.F. Madigan, T.M. Swager, V. Bulović, Sensitivity gains in chemosensing by lasing action in organic polymers, Nature 434 (2005) 876-879.

[24] T. Renkecz, G. Mistlberger, M. Pawlak, V. Horváth, E. Bakker, Molecularly im printed polymer microspheres containing photoswitchable spiropyran-based binding sites, ACS Appl. Mater. Interfaces 5 (2013) 8537-8545.

[25] G. Wulff, The role of binding-site interactions in the molecular imprinting of polymers, Trends Biotechnol. 11 (1993) 85-87.

26] F. Du, G. Ruan, S. Liang, F. Xie, H. Liu, Monolithic molecularly imprinted solidphase extraction for the selective determination of trace cytokinins in plant samples with liquid chromatography-electrospray tandem mass spectrometry, Anal. Bioanal. Chem. 404 (2012) 489-501.

[27] M.-M. Zheng, R. Gong, X. Zhao, Y.-O. Feng, Selective sample pretreatment by molecularly imprinted polymer monolith for the analysis of fluoroquinolones from milk samples, J. Chromatogr. A 1217 (2010) 2075-2081.

[28] D. Djozan, T. Baheri, Preparation and evaluation of solid-phase microextraction fibers based on monolithic molecularly imprinted polymers for selective extraction of diacetylmorphine and analogous compounds, J. Chromatogr. A 1166 (2007) 16-23.

[29] P. Gilli, V. Bertolasi, V. Ferretti, G. Gilli, Evidence for Intramolecular NH . . . O resonance-assisted hydrogen bonding in $\beta$-enaminones and related heterodienes. A combined crystal-structural, IR and NMR spectroscopic, and quantum-mechanical investigation, J. Am. Chem. Soc. 122 (2000) 10405-10417.

[30] D. Braga, L. Maini, F. Grepioni, A. De Cian, O. Félix, J. Fischer, M.W. Hosseini, Charge-assisted $\mathrm{N}-\mathrm{H}^{(+)} \cdots \mathrm{O}^{(-)}$and $\mathrm{O}-\mathrm{H} \cdots \mathrm{O}^{(-)}$hydrogen bonds control the supramolecular aggregation of ferrocenedicarboxylic acid and bis-amidines, New J. Chem. 24 (2000) 547-553.

[31] J.C. Ma, D.A. Dougherty, The cation- $\pi$ interaction, Chem. Rev. 97 (1997) 1303-1324.

[32] E.A. Meyer, R.K. Castellano, F. Diederich, Interactions with aromatic rings in chemical and biological recognition, Angew. Chem. Int. Ed. 42 (2003) 1210-1250.

[33] M. Kawano, J. Hasegawa, T. Enomoto, H. Onishi, Y. Nishio, M. Matsuda, T. Wakimoto, Hydroxylated polychlorinated biphenyls (OH-PCBs): recent advances in wildlife contamination study, Environ. Sci. 12 (2005) 315-324. 
[34] C.D. Sandau, P. Ayotte, E. Dewailly, J. Duffe, R.J. Norstrom, Analysis of hydroxylated metabolites of PCBs (OH-PCBs) and other chlorinated phenolic compounds in whole blood from Canadian inuit, Environ. Health Perspect. 108 (2000) 611-616.

[35] Y.F. Shi, H. Lin, D.M. Huang, Q. Gong, Y.Q. Cai, Y. Wang, B.B. Qian, Determination of hydroxylated polychlorinated biphenyls in mouse tissues and blood by gas chromatography/mass spectrometry, Chin. J. Anal. Chem. 38 (2010) 1345-1348.
[36] S. Rayne, K. Forest, pKa values of the monohydroxylated polychlorinated biphenyls (OH-PCBs), polybrominated biphenyls (OH-PBBs), polychlorinated diphenyl ethers (OH-PCDEs), and polybrominated diphenyl ethers $(\mathrm{OH}-$ PBDEs), J. Environ. Sci. Health Part A-Toxic/Hazard. Subst. Environ. Eng. 45 (2010) 1322-1346. 